\title{
WRITING STRATEGIES OF TUNISIAN MA HISTORY STUDENTS
}

\author{
SABIHA CHOURA \\ Assistant, English Department, Faculty of Arts and Humanities of Sousse \\ Tunisia Laboratory of Approaches to Discourse, Sfax, Tunisia
}

\begin{abstract}
Writing is difficult to master for foreign language learners. In the Tunisian context, English is a foreign language with French as a second language and Standard Arabic as a first language. Despite learning English for at least eleven years, first year Tunisian MA history students still find writing paragraphs in English difficult. To explore the challenges which first year Tunisian MA history students face in writing in English, an experiment in which they are asked to produce a short paragraph about a content specific topic is carried out. The present paper shows that even advanced learners studying History make various grammar and vocabulary errors reflecting their writing strategies. These errors are attributed, among other reasons, to various psycholinguistic phenomena, including negative transfer, borrowing, overextension of analogy, avoidance, overgeneralization, inadequate contextual use of grammatical forms, etc.
\end{abstract}

KEYWORDS: Foreign Language, Negative Transfer, Overgeneralization, Writing skill, Grammar \& Vocabulary

Received: Jun 09, 2017; Accepted: Jun 28, 2017; Published: Jul 05, 2017; Paper Id.: IJELAUG20174

\section{INTRODUCTION}

According to Haynes (2007, p. 61), "writing is one of the most difficult language skills for ELLs to master." Among the four skills students are required to master, this productive skill is a daunting task for learners as "[i]t involves the development of a design idea, the capture of mental representations of knowledge, and of experience with subjects" (József, 2001, p.5). That is, writing requires that students develop their abstract ideas into concrete words. While producing sentences, students should show a good mastery of various components such as grammar, vocabulary, punctuation and organization. The writing task becomes even more difficult for learners who are developing this productive skill in a language other than their first language. This explains the proliferation of research on learning writing in a foreign or second language context. Previous research includes the work of Sasaki (2009) who examines the pieces of writing of freshmen Japanese university students taking into consideration three variables: the writing ability of the students, their motivation and the effects of "SA experiences on L2 writing" (Sasaki, 2009, p. 52). Other researchers such as Flowerdew and Li (2009) investigate how Chinese scholars in various disciplines write for international publication.

Although various studies focusing on the writing skill in second language learning contexts have burgeoned, research concentrating on the writing skill in an L3 writing context is lacking. As Williams and Hammarberg (1998, p. 295) claim,

Discussion of cross-linguistic influence has focused almost exclusively on the role of L1 in L2 production, both in the form of cross-linguistic influence on the learner's interlanguage and in the form of 
language switches to the L1 during L2 production.

Among the studies on L3 writing, one can cite Gibson, Hufeisen and Libben (2001) who investigate how learners of German as an L3 learn and produce prepositional verbs. Other studies include that of Williams and Hammarberg (1998) who analyze language switches in L3 production taking Swedish as a case study. Thomas (1990) also focuses on Japanese as a third language and in particular on the acquisition of the pronoun "zibun". The proliferation of studies in this line of research has been explained by the fact that "there has been little work done on the influence of a learner's other previously learned L2s in the acquisition of a new language (L3)" (Williams \& Hammarberg, 1998, p. 295).

The present research attempts at exploring the writing strategies of first year Tunisian MA history students learning English (L3) as a foreign language. In the Tunisian context, Standard Arabic is considered as students' first language, whereas French is seen as their second language. As for English, it is Tunisian students' foreign language. As a foreign language, English is taught starting from sixth form basic education until advanced levels of study at universities in order to ensure that students develop good mastery of this language. Teaching English is aimed at developing the four following skills: reading, writing, speaking and listening. However, unlike French or Arabic, English is taught in its own right; that is, English is not used as a medium to teach other subjects like Mathematics or Physics.

Being exposed to the English language in institutional settings for this relatively long period of time, Tunisian students, though being at advanced levels, still face many difficulties. The present research limits its focus to the writing skill seeing its importance in academic literacy. This importance stems from the fact that English is the language of globalization and that the participants in the present research, that is, MA history students, are senior scholars who are really in need of the English language in order to meet the requirements of their discipline. In other words, through the English language, these novice researchers can voice their presence in their respective disciplines through presenting their new findings and can defend their cultures. Despite the importance of the writing skill and the fact that learners have developed it for eleven years, they do not engage in extended writing tasks as the activities they are designed are usually either controlled or semi-controlled including fill in the gap activities, keyword paragraphs and paragraph or sentence completion. Put differently, Tunisian students, except for English majors, are rarely engaged in free writing tasks. Even when they do so, they are asked to produce no more than one paragraph. This focus on analyzing the pieces of writing of postgraduate students, in particular, has been justified by Lillis' claim (2001, p. 33) that "official discourse on the 'problem' of student academic writing in higher education ignores much recent thinking on language and literacy generally and research on student writing more specifically." Taken together, the present paper aims at finding out the problems in grammar and vocabulary which first year Tunisian MA history students face while writing in the English language and at exploring the writing strategies accounting for their errors.

\section{METHODS}

\section{Participants}

The participants taking part in this research are university postgraduate students. Their number is twenty two. They are enrolled in their first year MA studies. They study English for one hour and a half per week. They take history courses in both Arabic and French. All the participants are Tunisian students who have pursued their studies in Tunisian institutions. For them, Standard Arabic is their first language and French is their second language. They have been studying English as a subject in its own right without seeing its relevance to other courses. 
The English course which first year Tunisian MA history students receive tries to improve their writing, speaking, listening and reading skills through providing them with a short text, the events of which are about Tunisian history. This includes, for example, a short text about the Ottoman Empire. The teacher starts the session by reading the text while the students keep listening. The texts form the starting point for the reading activity whereby students are required to read the text, to answer three to four questions and to explain particular vocabulary items. Students' answers are discussed with the whole class and the teacher. Afterwards, one grammatical notion illustrated in the text is explained and practiced. These pave the way for the writing activity whereby the students are asked to write down a short paragraph about the same topic while considering the keywords provided by the teacher.

\section{Experiment}

The present research attempts to assess MA students' writing ability in L3 production through identifying their errors. Before starting the experiment, I obtained the consent of the students and informed them that the writing task is not meant for evaluation, but it rather has pedagogical purposes as it aims at finding out their errors in order to help them to improve their writing skill.

The sample was obtained based on clinical elicitation (Corder, 1981, p. 29) whereby the participants were asked to produce any type of language data as opposed to experimental elicitation by means of which participants provide data containing particular linguistic features, the ones the researcher wants to investigate. In other words, by the end of the first term, I asked the students to write down a short paragraph not exceeding fifteen lines. The participants were required to "write down a short paragraph about the relationship between the Sunni and the Shia." The students were provided with keywords to help them. The keywords were as follows: "Islam", "Crusade", "tyrant"'“persecution", "non-Arab Muslims", "Kutama Berbers of the Kabylie region", "Aghlabids" and "reject". The participants were not allowed to consult any documents while writing this paragraph. They were allotted half an hour to do the task. The writing process was anonymous; that is, during the experiment, the students were asked not to mention their names as age and gender were not taken into consideration.

\section{Classificatory Grid}

After collecting participants' pieces of writing, I designed a grid classifying learners' errors into two categories: vocabulary and grammar, each of which was analyzed via a set of criteria. In fact, the study of vocabulary took place at two levels: inaccurate vocabulary items and inadequate vocabulary items in context. As for grammatical errors, they were classified into seven categories: subject-verb agreement, relative pronouns, determiners, singular versus plural nouns, prepositions, possessive case and voice.

\section{RESULTS AND DISCUSSIONS}

Since students' errors were classified into two categories: vocabulary and grammar, each of which will be devoted one sub-section. That is, quantitative and qualitative analyses accounting for first year Tunisian MA history students' errors at these two levels will be conducted. The distribution of vocabulary and grammar errors can be better seen in the following figure: 


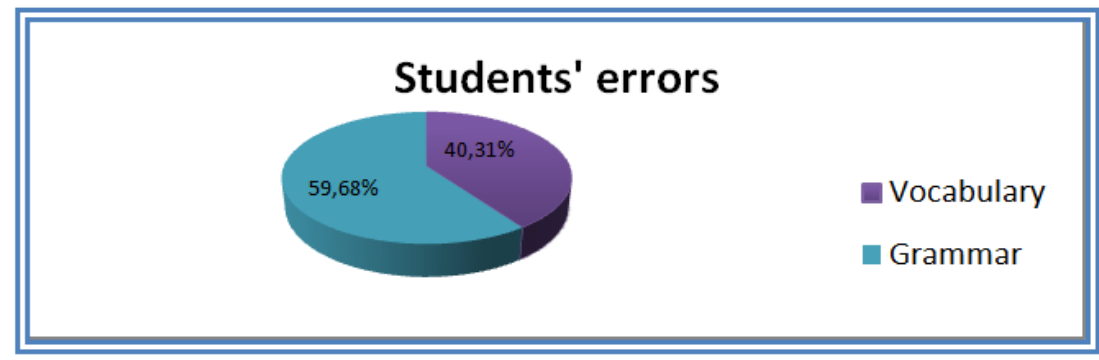

Figure 1: Distribution of Grammar and Vocabulary Errors

The analysis has shown that first year Tunisian MA history students make 59.50\% grammatical errors in comparison with $40.49 \%$ vocabulary ones. The finding that grammatical errors are more frequent than vocabulary ones may be explained by the fact that students are assessed on a topic related to their field of expertise, i.e. history. In the context of the present research, they are asked to produce a paragraph about the relationship between the Sunni and the Shia. The difference in the distribution of grammatical and vocabulary errors can also be related to the students' second language (i.e. French) and their foreign language (i.e. English). These two linguistic systems share many similarities. For instance, the word "refuse" and "division" are used in both French and English with more or less the same meaning. Thus, students' less frequent errors in vocabulary are explained by "positive transfer"(Ellis 1994; Nemser 1971; Selinker 1972) in similar terms such as "relation" and "respect". As Eslami and Noora claim (2008, p. 303), "[p]ositive transfer... provides facilitating effects on acquisition due to the influence of cross-linguistic similarities."

\section{Vocabulary}

Vocabulary errors are classified into two types. Their frequencies are presented in the following table:

Table 1: Vocabulary Errors

\begin{tabular}{|l|c|c|c|}
\hline \multicolumn{1}{|c|}{ Errors } & $\begin{array}{c}\text { Inaccurate } \\
\text { Vocabulary Items }\end{array}$ & $\begin{array}{c}\text { Inadequate Vocabulary } \\
\text { Items in Context }\end{array}$ & Total \\
\hline Numbers & 88 & 41 & 129 \\
\hline Frequencies & $68.21 \%$ & $31.78 \%$ & $100 \%$ \\
\hline
\end{tabular}

As can be seen in Table 1, vocabulary errors are of two types: those errors showing students' inaccurate use of vocabulary items and those resulting from the inadequate choice of the suitable vocabulary items in the appropriate context.

Concerning errors of the first type, they are partly attributed to the students' background knowledge of French as an L2. In fact, once faced with any difficulties in expressing their ideas in the English language, students activate their French mental lexicon instead of the English one. For example, one participant used the word "raison" instead of the word "reason". This overt error shows that the participant chose the French form "raison" which has the same meaning as the word "reason" in English. This is what Ringbom (1983, p. 207) refers to as "borrowing". In his words, "in borrowing, the search for an individual lexical item activates a word in another language, and... this item is taken over into the L2 in a modified or unmodified form, but a form non-existent in that language." Borrowing, in such a way, is seen as the easiest way allowing first year Tunisian MA history students to overcome the gap in their vocabulary knowledge. As Kharitonova (2013, p. 27) maintains, "[b]orrowing is mechanical and based on the only formal similarity between the words." 
Though borrowing from the French language, first year Tunisian MA history students do not follow the same strategy when it comes to their first language, i.e. Standard Arabic. This reliance on the French language and not on Standard Arabic may be traced back to the shared origins of both languages: French and English. For instance, the word "reason" in English and the word "raison" in French originate from Latin. This is inconsistent with Kellerman's claims that "there are enormous quantities of evidence for the influence of the L1 on IL when it comes to lexis" (1984, p. 115). This is, however, explained by the similarities between the two languages as is supported by Ringbom (2007). As Ringbom (2007, p. 86) puts it, "lexical errors due to non-native transfer are nearly always the outcome of item transfer normally based on an assumed cross-linguistic formal similarity."

As for vocabulary errors of the second type, the analysis has shown that they represent only $31.53 \%$. Although first year Tunisian MA history students write down accurate vocabulary items, they use them in inappropriate contexts. For example, instead of using the word "guide" which means "a person whose job is showing a place or a particular route to visitors", the student should have chosen the word "leader". Likewise, instead of selecting the word "branch" in the phrase "two branches of Islam", the student should have written down "sects". These are instances of semantic transfer. In other words, Tunisian first year MA history students seem to think in French and translate their thoughts into English.

The shared history of both languages leads students to misuse some vocabulary items. For instance, the word "infidèle" in French means unfaithful which is in this context the meaning that the participant wants to convey. However, by using the term "infidel" when writing in the English language, the student subverts the actual meaning s/he intends to transmit. This word refers to a person who holds different religious beliefs from a particular group of believers. This misuse of the word "infidel" illustrates what Ringbom (1983) refers to as "lexical transfer"; in other words, lexical transfer occurs "when semantic features are taken over, i.e. the semantic range of a target language word is modified on the model of an equivalent source language word, which in some contexts can be used as an equivalent" (Ringbom, 1983, p.207). This shows that the participant forms a different semantic mapping of this word based on its basic meaning in their second language. This is what Ellis (1994, p.59) refers to as "overextension of analogy". It "occurs when the learner misuses an item because it shares features with an item in the L1" (ibid.).

Likewise, the sentence "the famous region of Shia was the Fatimid" contains accurate English words, but the term "region" does not fit the context. This is attributed to semantic transfer. Since these students do not master the English language very well, they seem to think in their first language, i.e. Standard Arabic, and translate their thoughts into the English language without taking into consideration the denotation and the connotation of the words in English. The phrase “the famous region of Shia” seems to originate from the following phrase in Arabic: "الجهة المشهورة بشيعيّتها".

Misuse of the suitable vocabulary items in the appropriate context cannot be merely attributed to the interference between the three linguistic systems which MA history students have been exposed to in Tunisian academic institutions, but it can also be traced back to their lack of knowledge. For instance, in the following sentence "this relation infected a cause to the persecution", the term "infected" does not convey the suitable meaning, which means that it should be replaced by another word like "generated." Similarly, in the clause "And killed the Aghlabis country", the verb "to kill" implies that the patient should be animate, a feature which does not characterize the noun phrase "the Aghlabis country". The student should have replaced this clause by either "and killed the Aghlabids" or "and destroyed the Aghlabid country".

\footnotetext{
${ }^{1}$ This definition has been taken from Cambridge Dictionary http://dictionary.cambridge.org/fr/dictionnaire/anglais/guide
} 
Likewise, in the sentence "We have three kinds of Muslims", all the words are accurate but the term "kind" is not appropriate for this context. It should rather be substituted by the term "sects". These errors show that first year Tunisian MA history students are not fully aware of the denotation and connotation of the words they use. This may be attributed to the type of writing activities Tunisian students get usually engaged in. These include gap-filling activities and guided activities. Although these students have been studying English for at least eleven years, they have been barely involved in free writing activities. This is not the case for the French language which is the students' second language. Obviously, the types of activities Tunisian students are involved in account for the inadequate though accurate vocabulary items they use in their pieces of writing. The interference from other languages may be explained by the fact that students unconsciously draw upon these linguistic systems as they are used to free writing activities in both French and Standard Arabic such as producing a five paragraph essay without any hints or guidance.

Taken together, vocabulary errors are traced back, among other reasons, to borrowing, lexical transfer and semantic transfer. Seeing that English is the students' third language and these students are less exposed to this language than to other languages including their first language, i.e. Arabic, and their second language, i.e. French, they face problems in selecting the vocabulary item which best conveys their meaning. In order to overcome these difficulties, they draw upon the French language seeing that many English and French words originate from Latin. The interference of the French language also results in negative transfer when it comes to cognates, i.e. those lexical items which are written in the same way but have different meanings. Interference does not only result from the French language but also from the Arabic one but to a lesser extent. This is especially clear when students start to think in Arabic and then translate their thoughts into the target language, i.e. English. Because of this semantic transfer, students fail to choose the appropriate vocabulary item in English. This finding is consistent with the claim of Wei (2003. p.59) that “the learner's prior knowledge of his/her native language and of the second language may influence the process of cognitive and linguistic adaptation in third language learning." Being partly caused by negative transfer, these errors are also due to MA history students' lack of knowledge concerning the denotation and the connotation of the English words they use. Although the meaning, in this case, is understood by the receiver, i.e. the teacher, it does not fit the context of the sentence.

Obviously, these errors urge the teachers to think about the previously adopted teaching methods. Indeed, they should design activities to highlight the similarities between the two languages: English and French. Furthermore, they should draw students' attention to the different meanings of cognates which cause a potential area of making errors for students. Likewise, they should involve students in integrated activities where they practice the new vocabulary and develop their writing skill. This contextualized use of vocabulary items in different situations helps students foster their knowledge of English vocabulary items and hence improves their writing ability.

\section{Grammar}

Concerning grammatical errors, they are divided into seven classes which are subject-verb agreement, pronouns, determiners, and singular versus plural nouns, prepositions, possessive case and voice. The different percentages of these classes of grammatical errors are shown in the table below:

Table 2: Grammatical Errors

\begin{tabular}{|l|c|c|}
\hline \multicolumn{1}{|c|}{ Grammatical errors } & Numbers & Frequencies \\
\hline Determiners & 42 & $21.98 \%$ \\
\hline Singular versus plural & 34 & $17.80 \%$ \\
\hline Pronouns & 24 & $12.56 \%$ \\
\hline
\end{tabular}




\begin{tabular}{|l|c|c|}
\hline Subject-verb agreement & 33 & $17.27 \%$ \\
\hline Prepositions & 35 & $18.32 \%$ \\
\hline Possessive case & 4 & $2.09 \%$ \\
\hline Voice Total & 19 & $9.94 \%$ \\
\hline \multicolumn{2}{|c|}{ To1 } & $\mathbf{1 0 0 \%}$ \\
\hline
\end{tabular}

Among the grammatical errors which first year Tunisian MA history students make is the misuse of the definite and indefinite articles. For example, one participant produces the following sentence: "the relationship between the Sunni and the Shia is the bad relation for many raison." In this sentence, instead of using the indefinite article "a" in the noun phrase "the bad relation", the student selects the definite article "the". The student, thus, makes a definite reference despite the fact that s/he is describing a relationship in general. This confusion between the definite and indefinite articles may be attributed to two main reasons: the instruction provided to the students on the one hand and their cognitive processes on the other hand. In fact, the instruction provided to the students is as follows: "write down a short paragraph about the relationship between the Sunni and the Shia". In this sentence, the word "relationship" is preceded by the definite article "the". Thus, the grammatical error in the noun phrase "the bad relation" may be seen as an instance of overgeneralization; that is, students assume that they should precede any instance of the word "relationship" by the definite article "the". From a cognitive standpoint, after the student reads the instruction, his/her mental processor is going to activate the definite article "the" and not indefinite articles. In other words, the stimulus in the instruction is likely to trigger the definite article and therefore to increase memory demands for it. Obviously, the recurrent use of the definite article instead of the indefinite one can be explained by students' overgeneralization strategy whereby, starting from the instructions provided to them which include three instances of the definite article "the" (i.e., "the relationship", "the Sunni" and "the Shia"), they generalize this use to different article positions in the noun phrase. To help students overcome this cognitive process resulting in erroneous writing, the teacher can provide pieces of writing, including accurate and inaccurate uses of definite and indefinite articles. Being exposed to errors, students will manage to understand the difference between definite and indefinite articles and to avoid these errors in future pieces of writing.

When it comes to possessive determiners, students do not select the appropriate one. In fact, rather than using the pronoun "their" in the following clause "because your islam based of many valeur", they include the pronoun "your". This pronoun, being one aspect of conversational speech, is frequently used in communication between the teacher and the students, which shows their frequent exposure to it. Although students are reminded of the different personal pronouns and are exposed to the pronoun "their" in the different reading extracts, they still make errors. This shows that MA history students are likely to rely on the main features of conversation rather than academic writing. Since MA history students are incapable to refer to antecedents using accurate possessive determiners, the teacher should design further activities to help them differentiate between the various uses of these determiners.

Concerning quantifiers and numerals preceding the heads in a noun phrase, the analysis has shown that first year Tunisian MA history students use a plural quantifier or numeral with a singular head noun. Examples like this include "many raison", "many valeur" and "many place". Using the head noun in its unmarked form with plural numerals or quantifiers implies that these students think that it is only the quantifier or the numeral which carries the indication of the plural and there is no need to have the corresponding mark of the plural in the following head noun. This overgeneralization leads students to use only singular nouns with plural quantifiers and numerals. This is what Richards (1970) refers to as "incomplete application of rules". This "involves a failure to fully develop a structure" (Ellis, 1994, p. 59). 
Accordingly, first year Tunisian MA history students follow an overgeneralization strategy whereby they completely ignore adding the marker of the plural to the head noun, assuming that the quantifier or the numeral carries the plural inflection. This "incomplete application of rules" may have resulted from the fact that these students think that only singular nouns are preceded by a determiner in phrases like "a student" and "an infant" whereas phrases like "children" and "students" are not. This is why the teacher should draw the learners' attention to the relationship between the different lexical items which can occupy the determiner position such as the definite article "the", the indefinite articles "a /an", quantifiers like "many" and numerals like "two", "three" and "four" and the heads following them. For example, students should be involved in activities, developing their awareness that the indefinite articles and the numeral "one" always precede a singular noun, but numerals such as "two", "three", and "four" come before plural nouns.

The quantitative analysis has shown the overreliance of MA history students on nominative personal pronouns which are namely I, he, she, it, we, you and they. Being the most frequent pronouns they are familiar with and exposed to, students seem to overgeneralize the use of these pronouns to different contexts. For example, in the following clause "The khalifa Moawiya attaked many Shia and killed he" and in the phrase "In we time", the students use the pronoun "he" instead of "him" and "we" instead of "our". This is not due to students' ignorance of accusative personal pronouns, but it is rather explained by the infrequent exposure to such pronouns, which explains why students forget them and extend the use of nominative personal pronouns to different sentence positions. This is what Richards (1970) refers to as "ignorance of rule restrictions".

Concerning relative pronouns, students seem to confuse the relative pronoun "where" and "to be" in the past, i.e. "were", used as an auxiliary verb. This is clearly shown in the following example: "Muslims the shia where founded by Ali". In fact, "were" and "where" are spelled in the same way except for the addition of the <h> letter in the word "where". They are also pronounced in the same way except for the vowel. These similarities in both spelling and pronunciation make students exchange the relative pronoun "where" for the verb to be "were". I would not classify this error as “overextension of analogy" to use Lott's terminology (1983) since both forms exist in the target language, i.e. English. I would rather consider it as "false concepts hypothesized" (Richards, 1970). In other words, students lack the pragmatic knowledge of each form leading to the inadequate contextual use of each one. The confusion between these two words may lead students to adopt the avoidance strategy whereby they avoid the relative pronoun "where" and use another one such as the relative pronoun "when". The following sentence illustrates this avoidance strategy: "the Shia is appared like a political groupe and conquered the Maghreb when they destroyed Kairouan.”

Obviously, the analysis of MA history students' use of pronouns has revealed that they overuse nominative personal pronouns as they are the ones they are most exposed to. This implies that teachers should further familiarize the students with accusative personal pronouns and possessive pronouns in addition to training them to use these pronouns. Students' failure to choose the appropriate pronoun may also stem from their avoidance strategy resulting from the confusion they have concerning the relative pronoun "where" and the verb "to be" in the plural, i.e. "were". Considering how places are important for history students to locate different events, there arises the need for further practice of the difference between these two forms.

As is shown in Table 2, with verbs other than the verb "to be", students are likely to use the plural form when the subject is in the singular. Examples of these grammatical errors include the following "And everyone want to killer the others" and "The rival migrate". The grammatical error at the level of subject-verb agreement is attributed to students' 
preference for the unmarked form. This lack of mastery of subject verb agreement may be seen in light of students' writing strategies. This is what I would refer to as ignorance of rule restrictions. This means that subject verb agreement has not become an acquired system of the students. In other words, putting the verbs in the singular has not become an automatic process which students go through.

However, this tendency for the unmarked form proves untrue when it comes to irregular verbs such as the verb "to be". In fact, MA history students use the finite form of the verb "to be" as an auxiliary or a main verb in the singular or the plural form. Examples showing this error include "The Sunni and the Shia is two branche", "The relationship between Sunni and Shia are very contrast", "This conflict relation were developed" and "and they was allied with the Kutama Berbers of the Kabylie region". Seeing that the verb "to be" is irregular and students have memorized both singular and plural forms in the past or in the present (i.e. "was/is" and "were/are"), they systematically use these forms rather than the bare infinitive or to-infinitive form. This shows that students learn, memorize and systematize the forms they are frequently exposed to. Even though students use the finite form of the verb "to be", they still make errors concerning subject-verb agreement. For example, in the following clauses "this conflict relation were developed" and "The Sunni and the Shia was two branches of Islam", the students misuse the singular and plural forms of the verb "to be". The student should have used the singular form of the verb "to be" in the first case and the plural form in the second one. This shows that MA history students acknowledge that "was" and "were" are the finite forms of the verb "to be", but they cannot really figure out which one is the plural or the singular form, which leads them to use these two forms interchangeably. This misuse is even worsened with the complexity of the noun phrase playing the role of the subject. In fact, in the following clause "The relationship between Sunni and Shia are very contrast", the noun phrase "The relationship between Sunni and Shia" is composed of the head "relationship" which is post modified by the prepositional phrase "between Sunni and Shia". When processing this long noun phrase, the student makes more cognitive effort in order to decide whether to choose a singular or plural verb. Long noun phrases, when coupled with students' lack of mastery of the singular and plural forms, represent a potential source of making errors.

Accordingly, the analysis has shown Tunisian MA history students' preference for the unmarked form. That is, they opt for conjugating the verb with all the pronouns using the bare infinitive form. This has revealed that the marker "s" of subject-verb agreement is not systematized in a way that its use becomes automatic. This proves that MA history students cognitively process unmarked forms easier than marked ones. This, in turn, implies that Tunisian teachers should further concentrate on the marked form more than they do on the unmarked one. In other words, they should design activities focusing mainly on singular subject verb agreement. Even for those students who can differentiate between the singular and plural forms of agreement between the subject and the verb, they still make errors with long noun phrases as subject, which means that the teacher should draw their attention to the fact that the verb agrees with the head of the noun phrase functioning as a subject. These conclusions raise one pedagogical problem; since these students do not have the same lacks, it becomes necessary for the teacher to follow differentiated instruction to help students overcome their difficulties.

This preference for the unmarked form proves unsustainable when it comes to the verb "to be". When using the verb "to be", students usually choose either the singular "was/is" or the plural form "were/are". This shows that the longer the exposure to a particular linguistic form, the better students will memorize it. This, therefore, calls practioners' attention to the importance of focusing on the difference between the singular and the plural forms; that is, they should design 
consciousness-raising activities allowing students to differentiate the cases requiring the singular form from those necessitating the plural one.

The study of prepositions has proven that first year Tunisian MA history students either use wrong prepositions or forget to use any. In fact, in the following examples "Based of many valeur" and "Any relation between the Sunni", the student uses "of" instead of "on" and "between" rather than "with". This shows that students use the most familiar prepositions randomly without any consideration of the context. This may be attributed to the variety of prepositions and the different meanings each preposition has. Furthermore, prepositions are idiosyncratically linked with other nouns and verbs. These factors necessitate that students practice more prepositions and learn which prepositions are associated with other verbs or nouns. This also reveals that students' lack of knowledge of the different prepositions and their meanings leads them to extend the use of the preposition to a variety of contexts in order to relate the different words in phrases. Therefore, the first strategy which students adopt while using prepositions is overgeneralization. The second strategy which they opt for is avoidance. This strategy can be better explained through the following example: "Two branche islam". The total absence of the preposition "of" from this phrase shows that the student completely ignores the preposition slot in order not to use the wrong preposition. Therefore, faced with the polysemous nature of prepositions and their idiosyncrasy, MA history students follow two strategies: overgeneralization which they adopt once they apply the prepositions they master to a variety of contexts and avoidance which they resort to when they leave the preposition slot without any preposition.

As for forming the possessive case using the apostrophe "s", the analysis has shown that first year Tunisian MA history students seem either to completely ignore the marker of the possessive or to include the possessive "s" while forgetting about the apostrophe. In fact, in the following phrase "Aliss rival", the student tries to conform as much as possible to the accurate target form through adding the "s", but s/he fails to do so as s/he writes down double "s" without the apostrophe. Other examples including the following phrases "Khalif center" and "The shia faith" do not contain any indices of the possessive case. These errors reflect students' confusion between two similar grammatical structures: possessive nouns and compound nouns. This leads them to activate the easiest grammatical structure, which requires the least cognitive effort. This explains why these two students opt for the compounding structure though in an inaccurate context. However, the inclusion of only the "s" without the apostrophe may be explained by the knowledge conflict which the students experience between their prerequisite knowledge and the French linguistic system which does not include the apostrophe. This fossilized error of forgetting the apostrophe may be attributed to the length of the period during which these students have been exposed to the possessive case. As their current English program does not include a review of this structure and almost no cases of apostrophe "s" are included in the reading extracts, they commit this error. Although the students have been exposed to this structure in previous years, they still forget it, which means that it is not memorized in their long-term memory. Students' errors result from first their incomplete application of rules and second their overgeneralization of the compounding structure to extend it to the possessive one. This draws teachers' attention to the fact that they need to concentrate on the possessive case and to design language awareness activities focusing on these two different structures: compounds and possessive nouns.

Concerning the active/passive voice, first year Tunisian MA history students are not able to recognize the contexts requiring the use of one voice instead of another. Examples illustrating this error are listed below: "Islam has dividing in two branches"; "The Shea had protected and supported by the non-Arab Muslims"; and "The conflit between the Sunni 
ones and the Shia was appeared". The first example should not be in the active voice; "Islam", being the subject of the clause, is inanimate and cannot perform any action. It should rather be the patient undergoing the action. Since it is the patient and it occurs in clause initial position, the passive voice should be used instead of the active one. In the second example, the subject "the Shea" is animate and refers to a group of human beings having a particular religion. As such, it can occupy the subject position in an active clause. However, the presence of the by phrase "by the non-Arab Muslims" entails that "the Shea" is the goal, and hence it necessitates the use of the passive voice. In the third example, the clause includes the intransitive verb "appear" which cannot be transformed into the passive voice since it is not complemented by any participants. Lack of knowledge of the thematic roles of the different participants and the type of verb complementation leads students to use the active and the passive voice randomly as "the last resort" when they become indecisive as to which voice they should use. Errors in using the active/passive voice are the result of "false concepts hypothesized." They "derive from faulty comprehension of distinctions in the target language" (Richards, 1970, p.14).

Accordingly, students' errors come as a result of their random use of each voice as they cannot really figure out when to use each. This draws teachers' attention to the necessity of designing activities which help the students to differentiate between the thematic roles of various participants and to understand how these roles determine the choice of one voice over another. Further exercises should also familiarize students with the different types of verb complementation which allow passivization.

The overall analysis has shown that, while writing, first year Tunisian MA history students follow different strategies such as borrowing, transfer, overgeneralization, avoidance, incomplete application of rues, false concepts hypothesized, etc. This finding partly supports the work of Selinker, Swain and Dumas (1975) who maintain that French children adopt three main strategies which are language transfer, overgeneralization and simplification. Like their study, some of first year Tunisian MA history students' errors are attributed to the two former strategies: language transfer and overgeneralization. The absence of the third strategy, i.e. simplification, and the variety of strategies which MA history students rely on may be traced back to the difference in age between the two participants in each study (i.e., children versus adult) and the linguistic background of the participants in the present research.

\section{CONCLUSIONS}

Obviously, this research has provided further support to the claim that learners find more difficulties when their linguistic background differs from the new learned language. It has also shown that adult learners commit more grammar than vocabulary errors when one of their previously learned languages shares common origins with the new learned one. Therefore, previous linguistic background is likely to foster vocabulary learning rather than grammar learning seeing the similarities between the new and previously learned languages. Furthermore, unlike the claims of Kellerman (1984), this research has shown that learners draw on the language which is similar to the new learned language rather than their native or first language.

Concerning vocabulary learning, the present research has proven that adult learners are more likely to produce inaccurate vocabulary items than to misuse them in the appropriate context. This shows that they draw on similar previous linguistic background to choose words from the target language lexicon. These lexical selections are primarily based on meaning. While focusing on meaning, learners are likely to disregard formal differences between their linguistic background and their target language. 
This research opens the door for studying the pieces of writing of other groups of learners including those studying Geography, Arabic, French and Sociology. A comparative study can also be conducted between students specialized in English and others learning English as one of the courses in the syllabus. Other studies could also investigate skills such as speaking and reading.

Like any piece of research, this one has its limitations. In fact, it is limited to the study of the writing skill only. Furthermore, the number of participants taking part in this research is limited to twenty two participants. A larger sample including first year Tunisian MA history students from different universities could be more insightful and could generate more generalizable results. The study is also limited to the analysis of grammar and vocabulary; other features such as the organization of clauses, punctuation, coherence and cohesion could be investigated.

\section{REFERENCES}

1. Ellis, R. (1994). The study of second language acquisition. Oxford: Oxford University Press.

2. Eslami, Z.R. \&Noora, A. (2008). Perceived pragmatic transferability of L1 request strategies by Persian learners of English. In M. Pütz, \&J. N. Aertselaer (Eds.), Developing contrastive pragmatics: Interlanguage and cross-cultural perspectives(pp. 301-334). Berlin: Mouton de Gruyter.

3. Flowerdew, J. \& Li, Y. (2009). The globalization of scholarship: Studying Chinese scholars writing for international publication. In R. M. Manchón (Ed.), Writing in foreign language contexts: Learning, teaching, and research(pp. 156-182). Bristol: Multilingual Matters.

4. Gibson, M., Hufeisen, B. \& Libben, G. (2001). Learners of German as an 13 and their production of German prepositional verbs. In J. Cenoz, B. Hufeisen, \& U. Jessner (Eds.), Cross-linguistic influence in third language acquisition: Psycholinguistic perspectives (pp.138-148). Clevedon: Multilingual Matters LTD.

5. Haynes, J. (2007). Getting started with English language learners: How educators can meet the challenge. Virginia: Association for Supervision and Curriculum Development (ASCD).

6. József, H. (2001). Advanced writing in English as a foreign language. Pécs: Lingua Franca Csoport.

7. Kellerman, E. (1984). The empirical evidence for the influence of LI on interlanguage. In A. Davis, C. Criper,\& A. P. R.Howatt (Eds.), Interlanguage (pp. 98 - 122). Edinburgh: Edinburgh University Press.

8. Kharitonova, A. (2013). Lexical transfer and avoidance in the acquisition of English phrasal verbs: Evidence from Russian and Norwegian learners of English (MA thesis). University of Oslo, Oslo.

9. Krashen, S. (1981). Second language acquisition and second language learning. Oxford: Pergamon Press

10. Lillis, T.M. (2001). Student writing: Access, regulation, desire. London/New York: Routledge.

11. Lott, D. (1983). Analyzing and counteracting interference errors. English Language Teaching Journal, 37 (3), $256-261$. doi: 10.1093/elt/37.3.256.

12. Nemser, W. (1971). Approximative systems of foreign language learners. International Review of Applied Linguistics, 9 (2), $115-123$.

13. Richards, J.C. (1970). A non-contrastive approach to error analysis. Paper presented at the TESOL Convention, San Fransisco, March, 1970.

14. Ringbom, H. (1983). Borrowing and lexical transfer. Applied Linguistics, 4 (3),207-212.doi: 10.1093/applin/4.3.207. 
15. Ringbom, H. (2007). Cross-linguistic similarity in foreign language learning. Clevedon: Multilingual Matters Ltd.

16. Sasaki, M. (2009). Changes in English as a foreign language students'writing over 3.5 years: A sociocognitive account. In R. M. Manchón (Ed.). Writing in foreign language contexts: Learning, teaching, and research (pp. 49-76). Bristol: Multilingual Matters.

17. Selinker, L. (1972). Interlanguage. International Review of Applied Linguistics in Language Teaching, 10 (1-4), 209232.doi:10.1515/iral.1972.10.1-4.209.

18. Selinker, L., Swain, M. \& Dumas, G. (1975). The interlanguage hypothesis extended to children. Language Learning, 25 (1), 139-152. doi: 10.1111/j.1467-1770.1975.tb00114.x.

19. Thomas, M. (1990). Acquisition of the Japanese reflexives zibun by unilingual and multilingual learners. Proceedings of the Tenth Second Language Research Forum, 701-718. University of Oregon.

20. Wei, L. (2003). Activation of lemmas in the multilingual mental lexicon and transfer in third language learning. In J. Cenoz, B. Hufeisen, \& U. Jessner (Eds.), The multilingual lexicon (pp. 57-70). Dordrecht: Kluwer Academic Publishers.

21. Williams, S. \&Hammarberg, B. (1998). Language switches in L3 production: Implications for a polyglot speaking model. Applied Linguistics, 19 (3), 295-333. doi: 10.1093/applin/19.3.295. 
